\title{
Invasive Plants Differentially Impact Forest Invertebrates, Providing Taxon-Specific Benefits by Enhancing Structural Complexity
}

\author{
Andrew P. Landsman ${ }^{1 *}$, John Paul Schmit ${ }^{2}$ and Elizabeth R. Matthews ${ }^{2}$ \\ ${ }^{1}$ National Park Service, United States Department of the Interior, Hagerstown, MD, United States, ${ }^{2}$ National Park Service, \\ United States Department of the Interior, Washington, DC, United States
}

Exotic plant species often negatively affect native herbivores due to the lack of palatability of the invading plant. Although often unsuitable as food, certain invasive species may provide non-nutritional ecological benefits through increased habitat structural complexity. To understand the potential for common invasive forest plant species of the eastern United States to benefit invertebrate communities, we examined the functional and taxonomic community composition of forest insects and spiders in long-term monitoring plots that contained invasive plant species. The extent of

\section{OPEN ACCESS}

Edited by:

Bruce Arthur Osborne,

University College Dublin, Ireland

Reviewed by:

Paulo A. V. Borges,

University of the Azores, Portugal

Klaus Birkhofer,

Brandenburg University of Technology

Cottbus-Senftenberg, Germany

*Correspondence:

Andrew P. Landsman

Andrew_Landsman@nps.gov

Specialty section:

This article was submitted to

Population, Community,

and Ecosystem Dynamics,

a section of the journal

Frontiers in Ecology and Evolution

Received: 17 March 2021 Accepted: 16 September 2021

Published: 05 October 2021

Citation:

Landsman AP, Schmit JP and Matthews ER (2021) Invasive Plants

Differentially Impact Forest

Invertebrates, Providing

Taxon-Specific Benefits by Enhancing

Structural Complexity.

Front. Ecol. Evol. 9:682140. doi: 10.3389/fevo.2021.682140 invasive plant species ground cover significantly altered spider community composition as categorized by hunting guild. Areas with higher invasive herbaceous and grass cover contained a higher abundance of space web-weaving and hunting spiders, respectively. Spider species richness and total invertebrate abundance also increased with greater invasive grass cover. Still, these trends were driven by just two invasive plant species, garlic mustard and Japanese stiltgrass, both of which have previously been shown to provide structural benefits to native invertebrate taxa. While these two species may improve the structural component of understory forest habitat, many invertebrate groups were not significantly correlated with other prevalent invasive plants and one species, mock strawberry, negatively affected the abundance of certain insect taxa. Particularly in forests with reduced native plant structure, invasive plant management must be conducted with consideration for holistic habitat quality, including both plant palatability and structure.

Keywords: spiders, non-native species, invasive plants, insects, Araneae

\section{INTRODUCTION}

Invasive plant species are widely known for the negative consequences they impose on native plants and are responsible for wholescale changes in plant communities and natural ecological systems. Such invasive species, when established in a novel environment, compete with native flora for space, nutrients, and pollination services (Mack et al., 2000). Species invasion may also cause subsequent, secondary ecological impacts to native herbivores. Particularly detrimental for specialist feeders, invasive plant species may reduce available nutrients and palatable plant biomass, may not comprise suitable sites for oviposition and larval development, and may represent phylogenetically disparate host taxa that prevent host-switching (Tallamy and Shropshire, 2009; Burghardt et al., 2010; Harvey et al., 2010a; Tallamy et al., 2010; Spafford et al., 2013; Grandez-Rios et al., 2015). While much of 
the literature regarding impacts of invasive plants to native animals has focused on these effects to herbivores, a better understanding requires a more holistic and comprehensive approach that includes other trophic levels and functional groups (Harvey et al., 2010b). Through traits related to growth habit, individual plant or stem density, nutrient cycling, and propensity for outcompeting native species, certain invasive plants may significantly alter the structural complexity of natural, forested habitats. The physiognomy of the forest understory affects the ability of animal species to undertake critical life history functions, including the ability to find shelter, hunt prey, or lay eggs. While not related to plant palatability or suitability for larval development per se, these non-nutritional factors may still influence the functional and taxonomic composition of the animal community.

Dependent upon habitat, local environmental conditions, and the specific species of invasive plant, such structural changes to natural habitats may result in primary and secondary impacts to native herbivores and their predators and parasitoids (Watling et al., 2011). The mechanism by which invasive plants provide ecological benefits to native species is often modification of habitat complexity or when the invading species provides a limiting resource, such as habitat structure (Crooks, 2002; Rodriguez, 2006). In other situations, an invasive species, singly or in concert with other invasive species, may increase preferred habitat or resource availability, when compared with extant, native species (Wolf et al., 2017; Maclagan et al., 2018; Valentine et al., 2020). Invasive plant species have been shown to augment structural complexity for breeding birds (Sogge et al., 2008; Overton et al., 2014; Shriver et al., 2021) and to enhance habitat suitability for mammals (Maclagan et al., 2018). Complex architecture of certain exotic shrub and grassland species can also provide protection from predators and parasites for native rodents (Dutra et al., 2011; Malo et al., 2012), resulting in a greater abundance of reptile and avian predators (Wolf et al., 2017).

Depending on individual plant growth habit and population density, invasive species may also differentially affect various invertebrate taxa and functional groups. For example, invasive species in forest habitats may contribute added depth and complexity to the leaf litter, ultimately benefiting cursorial beetle and spider predators (Bultman and DeWitt, 2008; McCary et al., 2016). Spiders are particularly responsive to changes in plant structural complexity due to reliance upon vegetation for web attachment points and for surface area upon which to hunt; however, such responses vary depending on hunting guild (Gibson et al., 1992; McNett and Rypstra, 2000; Schmidt and Rypstra, 2010; Landsman and Bowman, 2017). Invasive herbaceous plants, including Alliaria petiolata (garlic mustard) and Centaurea maculosa (spotted knapweed), are known to create complex structure to support space web weaving spiders (Pearson, 2009, 2010; Smith-Ramesh, 2017), while Solidago canadensis (Canadian goldenrod) may benefit space and orb web weaving spider densities as well as their prey (Dudek et al., 2016). Invasive grass Microstegium vimineum (Japanese stiltgrass) benefits hunting wolf spiders (Lycosidae: Hogna spp.) in deciduous forests by increasing habitat structure and resulting in greater densities of both the spiders and their prey
(DeVore and Maerz, 2014). The same grass species also provides shelter for a greater abundance of detrital-based prey as well as spider taxa and functional groups (Landsman et al., 2020). Salt marsh invasion by Elymus athericus in France increased densities of one wolf spider species (Arctosa fulvolineata) while another species (Pardosa purbeckensis) declined as a result of altered prey abundance and increased intraguild competition (Pétillon et al., 2005, 2009). Additionally, the invasive shrub Lonicera maackii (Amur honeysuckle) provided increased architecture for all spider functional groups and their prey (Loomis et al., 2014).

Exotic species interactions and relationships that result in neutral or benign ecological effects are less frequently published than those resulting in positive or negative effects; however, these instances are much more likely to occur given the ratio of introduced species that become invasive in their new environment (Williamson and Fitter, 1996; Schlaepfer et al., 2011). Some introduced species may never become invasive, others may persist for years prior to becoming invasive, and some species may experience local population crashes after a period of rapid growth (Mack et al., 2000; Simberloff and Gibbons, 2004; Simberloff, 2011). Several studies that focused on the effect of established, invasive plants on insect-mediated pollination of native plants have found neutral to slightly positive effects on native plant pollination services (Stubbs et al., 2007; Nielsen et al., 2008; Charlebois and Sargent, 2017), with hypothesized negative impacts occurring with greater invasive plant density (Muñoz and Cavieres, 2008). In a meta-analysis of invasive plant effects to animal taxa, Schirmel et al. (2016) noted overall negative ecological effects; however, $44 \%$ of reviewed articles noted neutral impacts.

The mid-Atlantic region of the United States (USA) contains numerous invasive exotic plant species, with novel species introductions occurring with regularity, in part due to the stressors from anthropogenic development. Despite the prevalence of invasive plant populations, a thorough understanding of the effects of plant invasion on invertebrate communities is not well known. Owing to differences both in invasive species growth habits and across invertebrate taxonomic and functional guilds, we hypothesize that exotic plants will differentially influence the structure and composition of the invertebrate community. We hypothesize that (1) invasive grass ground cover will be positively correlated with the abundance of hunting spiders, detritus-based insect taxa, and spider taxa that depend on such detrital food webs, (2) invasive herbaceous plants will benefit space web weaving spiders, (3) greater invasive shrub cover will provide beneficial structure to increase abundance of web building spider groups, and (4) cumulative ground cover of various invasive species will directly reduce densities of insect herbivores while not significantly affecting other insects.

\section{MATERIALS AND METHODS}

\section{Vegetation Sampling}

To identify correlations between invasive vegetation and forest invertebrate communities, we utilized long-term monitoring plots established by the United States National Park Service to 
track changes in forest vegetation. Forest vegetation plots were initially identified in 2006 using a spatially balanced generalized random tessellation stratified sampling design (Stevens and Olsen, 2004). We selected all 30 extant forest monitoring plots within a $120-\mathrm{km}$ linear span of National Park Service property adjacent to the Potomac River within the Chesapeake and Ohio Canal National Historical Park in Washington, Frederick, and Montgomery Counties in Maryland, United States (Figure 1). Forest plots were characterized by Acer spp. (maple), Quercus spp. (oak), and Robinia pseudoacacia (black locust) in the overstory and Ulmus americana (American elm) and Asimina triloba (pawpaw) in the understory and low mid-story. The shrub layer consisted mostly of Lindera benzoin (northern spicebush).

Each plot consisted of a $15-\mathrm{m}$ radius circle, divided into subplots to sample various forest vegetation classes. Ground cover was sampled within twelve $1-\mathrm{m}^{2}$ quadrats, with nine quadrats oriented in three equidistant transects at 0,120 , and 240 degrees from magnetic north and three additional quadrats, $10 \mathrm{~m}$ from plot center at 60, 180, and 300 degrees. To the nearest percent, we visually estimated the percent ground cover of 21 targeted invasive plant species within each quadrat (Table 1). Targeted invasive plant species were those which are the most prevalent or noxious invasive species and are spreading in the mid-Atlantic US. We also estimated total ground cover of bryophytes, sedges, ferns, and non-invasive grasses and herbs present in the quadrats. We estimated ground cover separately for each species and growth form. Total cover in a quadrat can be over $100 \%$ when different growth types of vegetation visually overlap. We recorded the abundance and diameter of all pieces of coarse woody debris intersecting the three 15-m transects. All plots are sampled for forest vegetation

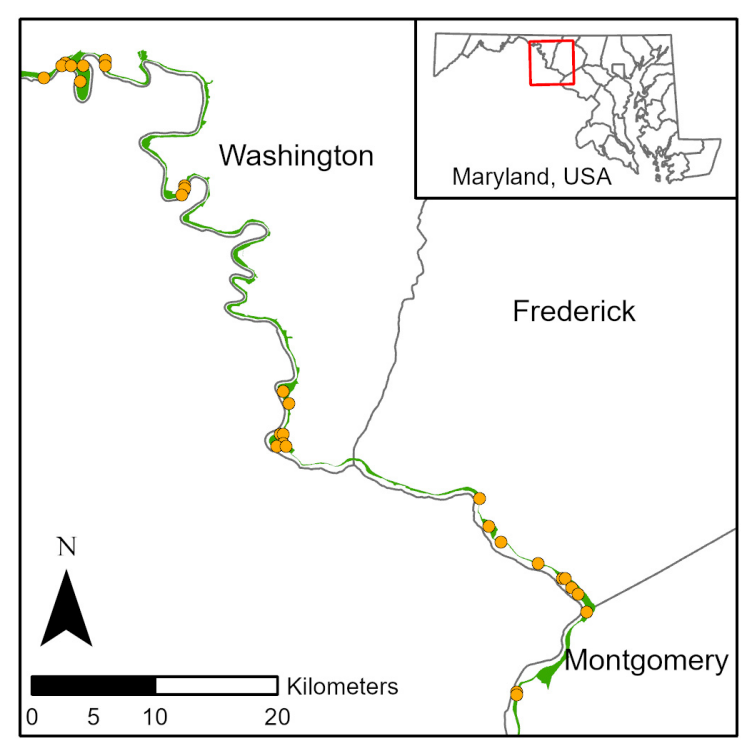

FIGURE 1 | Contextual map of study area showing location of plot centroids in Washington, Frederick, and Montgomery counties, Maryland, United States.
TABLE 1 | Independent variables and mean and SE values identified in sampling plots across the study area in Washington, Frederick, and Montgomery counties, in Maryland, United States.

\begin{tabular}{|c|c|}
\hline Independent variable & Mean \pm SE \\
\hline Invasive plant richness & $6.62 \pm 0.41$ \\
\hline Abundance of coarse woody debris & $4.55 \pm 0.59$ \\
\hline Mean diameter of coarse woody debris (cm) & $14.87 \pm 1.29$ \\
\hline Cumulative percent invasive species ground cover & $50.57 \pm 5.20$ \\
\hline Abundance of non-spider invertebrates & $166.86 \pm 16.71$ \\
\hline Percent cover invasive grasses & $25.93 \pm 4.54$ \\
\hline Microstegium vimineum & $25.93 \pm 4.54$ \\
\hline Percent cover invasive herbs & $11.72 \pm 2.58$ \\
\hline Alliaria petiolata & $7.16 \pm 1.82$ \\
\hline Duchesnea indica & $1.62 \pm 0.42$ \\
\hline Perilla frutescens & $0.20 \pm 0.10$ \\
\hline Polygonum caespitosum & $2.28 \pm 1.05$ \\
\hline Polygonum persicaria & $0.17 \pm 0.16$ \\
\hline Percent cover invasive shrubs & $5.60 \pm 2.94$ \\
\hline Berberis thunbergii & $1.28 \pm 0.82$ \\
\hline Lespedeza cuneata & $0.01 \pm 0.01$ \\
\hline Rosa multiflora & $3.78 \pm 2.15$ \\
\hline Rubus phoenicolasius & $0.54 \pm 0.25$ \\
\hline Percent cover invasive vines & $6.25 \pm 1.72$ \\
\hline Ampelopsis brevipedunculata & $<0.01 \pm<0.01$ \\
\hline Celastrus orbiculatus & $0.064 \pm 0.44$ \\
\hline Clematis terniflora & $0.01 \pm 0.01$ \\
\hline Euonymus fortunei & $0.01 \pm 0.01$ \\
\hline Glechoma hederacea & $1.60 \pm 0.86$ \\
\hline Hedera helix & $0.06 \pm 0.03$ \\
\hline Humulus japonicus & $0.06 \pm 0.04$ \\
\hline Lonicera japonica & $1.50 \pm 0.45$ \\
\hline Lysimachia nummularia & $2.21 \pm 1.21$ \\
\hline Wisteria floribunda & $0.04 \pm 0.04$ \\
\hline Percent cover remaining vegetation & $23.28 \pm 3.32$ \\
\hline
\end{tabular}

within a 4-year panel design, and for analysis we used the sampling date (2016-2019) closest to invertebrate sampling. The complete long-term vegetation monitoring protocol is described in Schmit et al. (2014).

\section{Invertebrate Sampling}

At each plot, we employed a bipartite sampling design to capture both cursorial and understory invertebrates. We used a 2-gal paint strainer bag affixed to a commercially available leaf blower and vacuum (Black + Decker LSWV36) to vacuum all plant surfaces and interstitial spaces for a standardized $8 \mathrm{~min}$ at each plot. We conducted vacuum sampling in late June and September, 2018 within a $2-\mathrm{m}$ wide buffer surrounding the circular plots to avoid trampling of vegetation within the plots (Figure 2). Larger invertebrates, including some spiders and assassin bugs (Reduviidae), were collected by hand if the vacuum was not strong enough to facilitate collection. At 120, 240, and 360 degrees from magnetic north, we centered a 0.5 by $0.5 \mathrm{~m}$ PVC square adjacent to the plot edge and collected all leaf litter, woody debris, and other organic material during the sample 


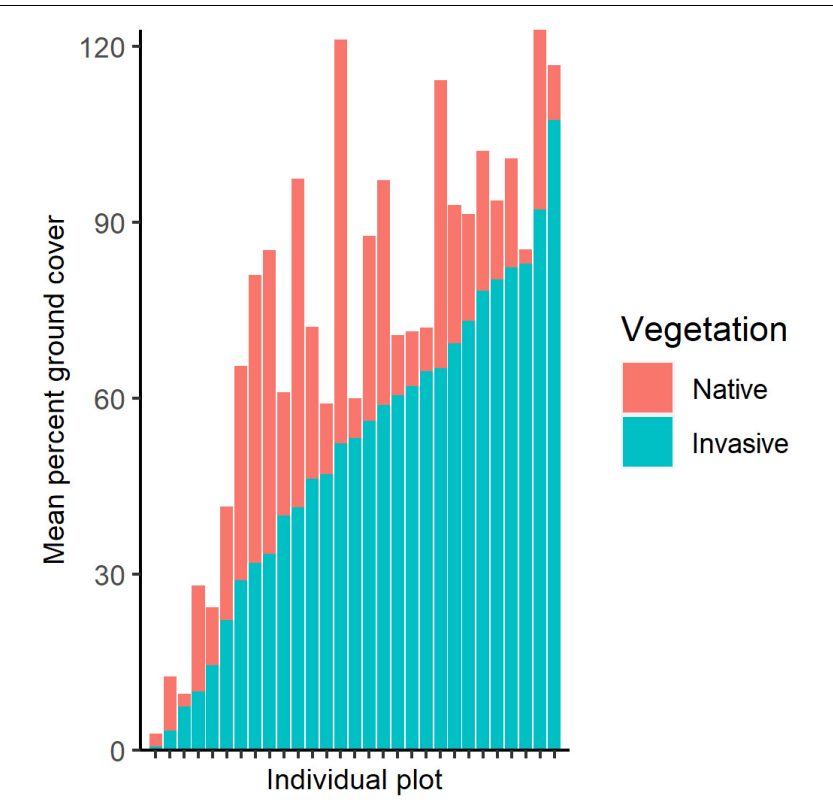

FIGURE 2 | Stacked bar chart showing mean percent ground cover of invasive and native vegetation within sampled quadrats, with each bar representing one plot. Percent ground cover can reach over $100 \%$ as cover is estimated at various heights to account for invasive shrubs and low-growing species.

period in September. We manually sorted through litter samples and collected specimens by hand and with use of an aspirator. All collected specimens from vacuum and litter samples were asphyxiated with ethyl acetate and subsequently placed into 95\% ethanol. We identified spiders to genus using Ubick et al. (2017) and insects to order using Triplehorn and Johnson (2005). We further subdivided insects into morphologically distinct taxonomic groups or morphospecies.

\section{Statistical Analysis}

For our analysis, we wished to account for the possibility that invertebrate abundance could be influenced by either individual invasive plants, or a combined effect of many species of a particular growth form, or both. Furthermore, impacts on the invertebrate community could occur at the level of individual taxonomic groups or across broader trophic behavioral groups. Therefore, our approach was to compare invertebrate abundance, summarized both taxonomically and by feeding behavior, to invasive ground cover, measured at the level of growth form or as individual species. Separate analyses were carried out on spider taxonomic communities at the genus level and to insects at the order and morphospecies level. Additionally, we analyzed the same data organized by trophic behavior. Generalized from the classification by Cardoso et al. (2011), we sorted spider taxa by those which weave orb webs, build space or sheet webs, and those that actively or passively hunt for prey (Supplementary Table 1). Insect groups were also categorized into the feeding guilds of detritivores and decomposers, predators and parasites, herbivores, and omnivores (Supplementary Table 2).
To assess correlations between the plant growth forms and invertebrate communities, we used package mvabund in program $\mathrm{R}$ 4.0.3 to fit multivariate generalized linear models with negative binomial probability distributions to the community data and conducted analysis of deviance tests to determine significance (Wang et al., 2012; R Core Team, 2020). Adjusted univariate test statistics were derived using a parametric bootstrapping procedure with 2,000 iterations to control error rates (Westfall and Young, 1993; Davison and Hinkley, 1997; Wang et al., 2012). Our model covariates included the percent ground cover of targeted invasive growth forms, namely grasses, herbs, vines, and shrub species observed in the quadrats, total percent ground cover of targeted invasive plant species, the abundance and mean diameter $(\mathrm{cm})$ of coarse woody debris, and species richness of invasive plants. We also used the total ground cover of remaining vegetation as an independent covariate and the abundance of non-spider invertebrate prey as a covariate in models for spiders.

We employed univariate generalized linear models with package MASS to detect correlations between the abundance and richness of spiders and insects and the percent cover of individual invasive plant species and growth forms (Venables and Ripley, 2002). Univariate models were fit with a negative binomial probability distribution or a Poisson distribution where overdispersion was not present as determined by function dispersiontest in package AER (Kleiber and Zeileis, 2008). $P$-values were obtained from likelihood ratio test statistics using Anova.glm. We visually assessed model fit using residual plots and by plotting model residuals against fitted values for each model. For multivariate models, we plotted Dunn-Smyth residuals against fitted values (Dunn and Smyth, 1996).

\section{RESULTS}

\section{Vegetation}

One monitoring plot became inaccessible during a portion of the study so it was excluded from analyses. Target invasive plants were prevalent (Table 1). Microstegium vimineum was the only invasive grass identified in the plots, with ground cover estimates ranging from 0 to nearly $74 \%$ with mean $25.93 \%$. We identified five invasive herbaceous plants, with A. petiolata, Duchesnea indica, and Polygonum caespitosum comprising the most dominant species. Ground cover of $A$. petiolata ranged from 0 to $40 \%$ with mean of $7.16 \%$, while $D$. indica ground cover ranged from 0 to $10 \%$ with mean of $1.62 \%$. Percent ground cover of all invasive herbs combined ranged from 0.2 to $55 \%$ with mean $11.72 \%$. Invasive shrubs consisted of four species and were less prevalent throughout the study area with mean of $5.60 \%$ ground cover. We also identified ten invasive vine species with mean $6.25 \%$ ground cover.

In addition to the targeted invasive species, remaining ground cover within the plots ranged from 2 to nearly $70 \%$ with mean of $21.86 \%$ cover (Table 1). Total ground cover of other bryophytes, ferns, grasses, sedges, and herbs was not correlated with our invasive plant metrics, except for a positive correlation with invasive herbaceous plants $(t=4.946, P<0.001, r=0.689)$ and A. petiolata $(t=3.390, P=0.002, r=0.546)$. Throughout the study 
area, the targeted invasive plant species comprised nearly twice the extent of ground cover as remaining vegetation in sample plots, with a mean cover of $70.00 \%$ for invasive plants and $36.10 \%$ for other vegetation (Figure 2).

\section{Spider Community Response to Vegetation}

We collected 610 individual spiders across 16 taxonomic families in vacuum and leaf litter samples. An additional 35 specimens were removed from analyses because they were either too damaged for proper identification or were unable to be identified beyond the superfamily Araneoidea. Anyphaenidae was the most commonly collected taxon in combined samples, followed by web building spiders in the Linyphiidae, Araneidae, and Tetragnathidae (Figure 3). Vacuum samples comprised nearly $90 \%$ of all collected specimens. Leaf litter samples consisted mostly of Lycosidae, with seven additional families represented, including wandering adult male araneoids.

Community structure of spider hunting guilds was significantly correlated with percent cover of invasive herbaceous $\left(G^{2}=8.002, P=0.035\right)$ and grass species $\left(G^{2}=8.132, P=0.040\right)$. Adjusted, resampling-based univariate tests showed that, within the spider community, the abundance of space web weaving species increased with greater invasive herbaceous plant cover $\left(G^{2}=7.524, P=0.011\right)$ whereas increased hunting spider abundance was marginally correlated with greater invasive grass cover $\left(G^{2}=4.811, P=0.068\right)$. The correlation observed with the spider functional community was driven by two specific invasive

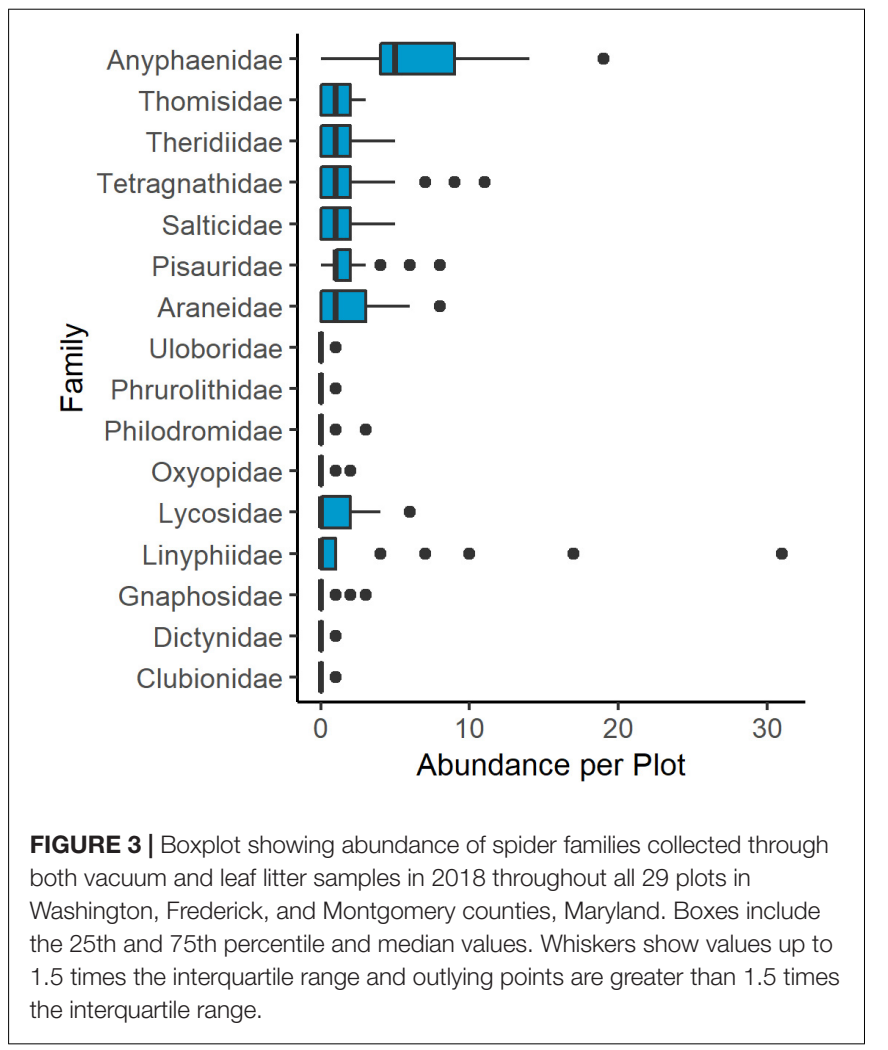

species: M. vimineum and A. petiolata (Table 2). Ground cover of $A$. petiolata had a stronger effect than all herbaceous species combined, when assessed in combination with $M$. vimineum $\left(G^{2}=10.623, P=0.008\right)$. Assessed outside of the multivariate framework, univariate testing similarly showed that greater A. petiolata cover was associated with an increased abundance of space web weaving spiders (Figure 4A; $G^{2}=9.885, P=0.002$ ) and $M$. vimineum was positively correlated with the abundance of hunting species (Figure $4 \mathrm{~B} ; G^{2}=6.910, P=0.009$ ).

Total spider abundance was not correlated with the abundance of invertebrates $\left(G^{2}=0.169, P=0.681\right)$. Similarly, we found no correlation between invertebrates and space web weaving spiders $\left(G^{2}=2.679, P=0.102\right)$ or hunting species $\left(G^{2}=0.114, P=0.736\right)$. Only the abundance of orb web weaving species was positively related to the abundance of invertebrates $\left(G^{2}=4.794, P=0.029\right)$. Similar to results with hunting guilds, total spider abundance was positively correlated with percentage ground cover of both $M$. vimineum $\left(G^{2}=5.521, P=0.019\right)$ and $A$. petiolata $\left(G^{2}=3.993\right.$, $P=0.046)$. Richness of the spider community, assessed at the genus level, increased with greater cover of $M$. vimineum $\left(G^{2}=4.910, P=0.027\right)$. The best predictor variable in community models of spider genera was the percent of ground cover of all invasive plant species $\left(G^{2}=78.042, P=0.005\right)$. Taxonomic community structure was similarly influenced by the percent ground cover of invasive vines $\left(G^{2}=75.459, P=0.027\right)$ and the abundance of coarse woody debris $\left(G^{2}=71.250, P=0.008\right)$, and was marginally correlated with the percent ground cover of D. indica $\left(G^{2}=66.980, P=0.071\right)$.

\section{Other Invertebrate Response to Vegetation}

We collected a total of 4,955 other invertebrates, not including the aforementioned spiders. Collected invertebrates were comprised of 11 insect orders, three non-spider arachnid orders (Acari, Opiliones, and Pseudoscorpiones), Collembola, and Gastropoda.

TABLE 2 | Correlations between spider community and invasive plant covariates.

\begin{tabular}{|c|c|c|c|c|}
\hline \multirow{2}{*}{$\begin{array}{l}\text { Dependent } \\
\text { variable }\end{array}$} & \multicolumn{2}{|c|}{ Mean cover of $A$. petiolata } & \multicolumn{2}{|c|}{ Mean cover of $M$. vimineum } \\
\hline & $G^{2}$ & $P$ & $G^{2}$ & $\boldsymbol{P}$ \\
\hline $\begin{array}{l}\text { Community } \\
\text { structure }\end{array}$ & 10.623 & 0.008 & 6.730 & $0.063^{*}$ \\
\hline $\begin{array}{l}\text { Orb web } \\
\text { spiders }\end{array}$ & 0.170 & 0.702 & 2.257 & 0.238 \\
\hline $\begin{array}{l}\text { Space web } \\
\text { spiders }\end{array}$ & 9.927 & $0.003(+)$ & 0.025 & 0.872 \\
\hline $\begin{array}{l}\text { Hunting } \\
\text { spiders }\end{array}$ & 0.527 & 0.702 & 4.447 & $0.088^{*}(+)$ \\
\hline $\begin{array}{l}\text { Total spider } \\
\text { abundance }\end{array}$ & 3.993 & $0.046(+)$ & 5.521 & $0.019(+)$ \\
\hline $\begin{array}{l}\text { Spider } \\
\text { species } \\
\text { richness }\end{array}$ & 1.176 & 0.278 & 4.910 & $0.027(+)$ \\
\hline
\end{tabular}

Statistical significance is denoted by bold text with asterisks noting only marginal correlation $(P<0.10)$. Direction of the correlation is indicated in parentheses. 

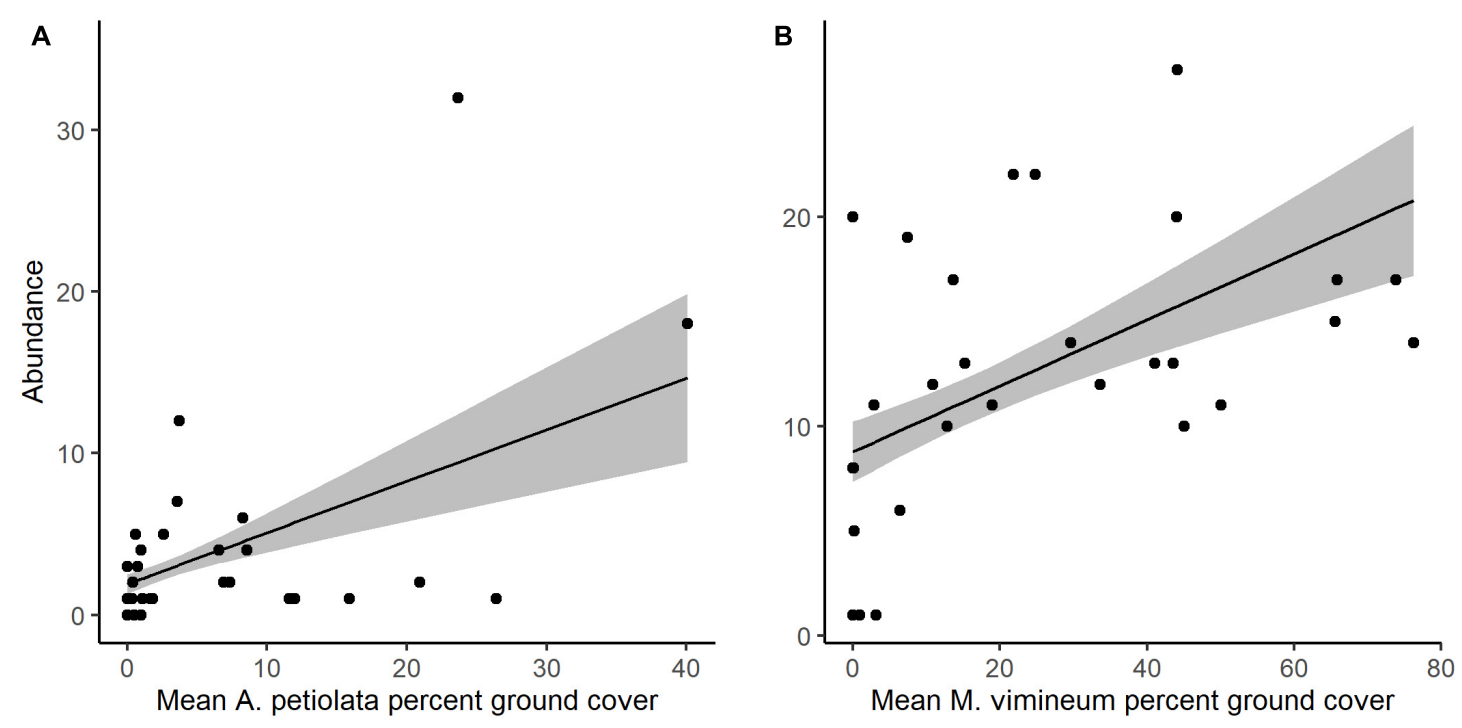

FIGURE 4 | Predicted response of (A) space web weaving spider abundance to ground cover of $A$. petiolata and (B) hunting spider abundance to ground cover of $M$. vimineum. Black points represent raw abundance data, lines depict fitted models, and gray shading represents $\pm 1 \mathrm{SE}$.

The insects and non-spider arachnids were further subdivided into 98 distinct morphospecies. Total invertebrate abundance increased with greater ground cover of $M$. vimineum both with spiders included $\left(G^{2}=5.235, P=0.022\right)$ and excluded $\left(G^{2}=4.244, P=0.039\right)$. Excluding spiders, the community structure of remaining invertebrate feeding guilds was also correlated with the percent ground cover of M. vimineum $\left(G^{2}=9.795, P=0.034\right)$; however, adjusted univariate tests did not identify significant relationships. When analyzed at the taxonomic order, invertebrate community structure was related only to ground cover of sedges $\left(G^{2}=43.892, P=0.002\right)$ and ferns $\left(G^{2}=39.322, P=0.007\right)$. Adjusted univariate tests did not identify significant relationships with either targeted invasive plants or other ground cover. Community structure, organized by individual morphospecies, mirrored the noted correlation with sedge ground cover $\left(G^{2}=151.021, P=0.004\right)$ and ferns $\left(G^{2}=131.161, P=0.006\right)$. Morphospecies community structure also exhibited significant correlations with both $A$. petiolata $\left(G^{2}=144.547, P=0.007\right)$ and $M$. vimineum $\left(G^{2}=156.430\right.$, $P<0.001$ ), with adjusted univariate tests only identifying a significant correlation between one leafhopper morphospecies (Hemiptera: Cicadellidae) and M. vimineum $\left(G^{2}=12.340\right.$, $P=0.038$ ). Separate, univariate generalized linear models also revealed significant relationships between individual insect orders and our invasive plant covariates (Table 3). Specifically, several insect groups (Collembola, Hymenoptera: Formicidae, and Lepidoptera) decreased in abundance with greater percent ground cover of invasive herbaceous plants (Figure 5). Greater cover of $M$. vimineum increased abundance of both predatory $\left(G^{2}=4.808, P=0.028\right)$ and herbivorous Hemiptera (Figure 6; $\left.G^{2}=4.050, P=0.044\right)$, and was marginally correlated with increased Diptera $\left(G^{2}=3.318, P=0.069\right)$. Driven by the relative abundance of Hemiptera, greater $M$. vimineum ground cover also increased the abundance of herbivores $\left(G^{2}=4.903\right.$,
$P=0.027)$. Increased ground cover of $D$. indica reduced the abundance of Collembola $\left(G^{2}=3.574, P=0.042\right)$ and Formicidae $\left(G^{2}=5.495, P=0.019\right)$.

\section{DISCUSSION}

Invasive plant species in the deciduous forests of our study area variously resulted in negative, positive, and non-significant impacts to the invertebrate community, depending on the plant species and invertebrate taxon and functional group. Such relationships are species-specific, varying with plant palatability and structural characteristics of the invading species. This variation highlights the need for holistic analysis to ensure a comprehensive understanding of the complex effects of invasive plant species. In our study area, $M$. vimineum and A. petiolata were most significantly correlated with various invertebrate groups as described below, while other invasive and exotic plant species did not significantly affect the insect and invertebrate predator communities. Although these two species both showed significant relationships with invertebrate community metrics, these were also the two most prevalent invasive species. The remaining 18 targeted invasive species were present throughout the study area; however, these populations were not present at levels that may cause demonstrable shifts, either positive or negative, in the invertebrate community (Muñoz and Cavieres, 2008).

Increased M. vimineum cover was associated with changes to the functional composition of the spider community, increasing the relative abundance of hunting spiders which catch prey on the forest floor; this plant species can form dense patches, increasing near-ground structural complexity, which may offer ideal habitat for hunting spiders. Similarly, insect community structure and composition included greater 
TABLE 3 | Correlations between selected insect groups and invasive plant covariates.

\begin{tabular}{|c|c|c|c|c|c|c|}
\hline \multirow[t]{2}{*}{ Dependent variable } & \multicolumn{2}{|c|}{ Mean cover of $D$. indica } & \multicolumn{2}{|c|}{ Mean cover of $M$. vimineum } & \multicolumn{2}{|c|}{ Mean cover of all invasive herbs } \\
\hline & $G^{2}$ & $\boldsymbol{P}$ & $G^{2}$ & $\boldsymbol{P}$ & $G^{2}$ & $P$ \\
\hline Invertebrate abundance & 2.461 & 0.117 & 4.315 & $0.038(+)$ & 0.196 & 0.658 \\
\hline Collembola & 3.574 & $0.042(-)$ & 0.164 & 0.685 & 4.144 & $0.042(-)$ \\
\hline Diptera & 1.999 & 0.157 & 3.318 & $0.069 *(+)$ & 0.125 & 0.724 \\
\hline Formicidae & 5.495 & $0.019(-)$ & 0.772 & 0.380 & 7.430 & $0.006(-)$ \\
\hline Hemiptera (herbivores) & 0.496 & 0.481 & 4.05 & $0.044(+)$ & 1.660 & 0.198 \\
\hline Hemiptera (predatory) & 0.038 & 0.845 & 4.808 & $0.028(+)$ & 0.036 & 0.849 \\
\hline Lepidoptera & 0.447 & 0.504 & 0.101 & 0.750 & 4.826 & $0.028(-)$ \\
\hline
\end{tabular}

Statistical significance is denoted by bold text with asterisks noting only marginal correlation $(P<0.10)$. Direction of the correlation is indicated in parentheses.

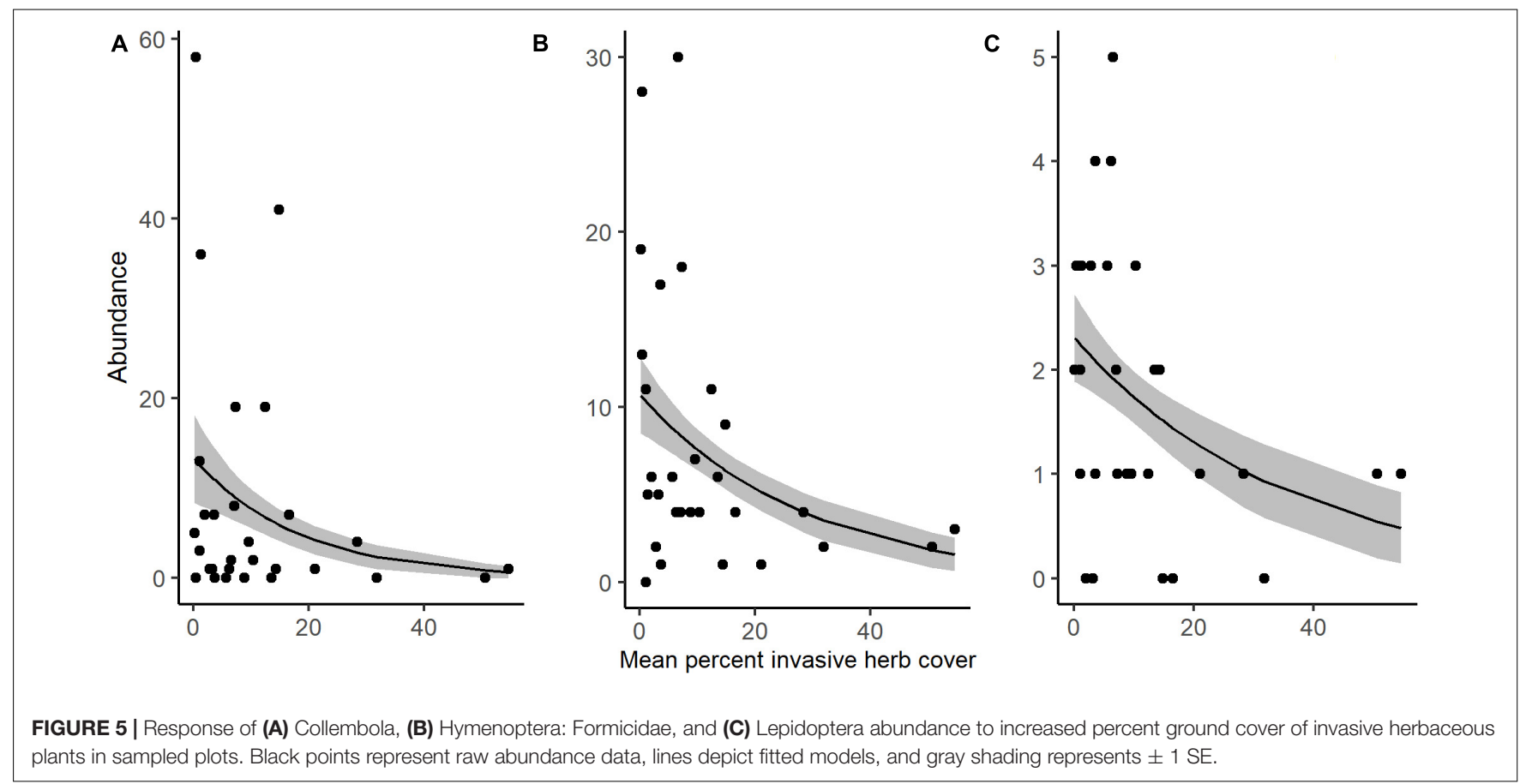

abundance of Hemiptera with greater M. vimineum ground cover. Ground cover of M. vimineum also increased richness of the spider community. These findings align with previous research that shows the importance of augmented structure in increasing abundance of detritus-based insects and their predators (Langellotto and Denno, 2004; McCary et al., 2016; Landsman et al., 2020). Hunting predators may benefit from the more complex physiognomy of the forest floor, particularly in response to invasive species, such as $M$. vimineum, that form dense mats (Bultman and DeWitt, 2008; DeVore and Maerz, 2014). As we hypothesized, detrital flies increased in abundance, albeit only with marginal statistical significance, with greater $M$. vimineum cover, perhaps due to the importance of enhanced near-floor structure (McCary et al., 2016). Herbivorous Hemiptera also increased in abundance with greater cover of M. vimineum, counter to our hypothesis but in corroboration with previous work with $M$. vimineum in this region of the eastern US (Landsman et al., 2020). Nearly $80 \%$ of collected Hemiptera were in the Cicadellidae (leafhoppers) which are known to occur in abundance within M. vimineum in similar habitats (Marshall and Buckley, 2009). Although many of these species may feed on grasses, it is unclear whether M. vimineum is a suitable host, is used as shelter, or if M. vimineum provides positive influence on soil moisture or microclimate.

Similarly, ground cover of invasive A. petiolata was also related to the community structure of spider hunting guilds, resulting in an increased relative abundance of space web weaving species. In its second year, A. petiolata establishes a tall stalk with a terminal inflorescence surrounded by siliques containing seeds. The whorled configuration of siliques provides unique architecture for small, space web spiders such as those in the Dictynidae, Theridiidae, and Linyphiidae, as has been shown in similar eastern US forests (Smith and Schmitz, 2015; Smith-Ramesh, 2017). The complex structure provided by the branched stem, leaves, and inflorescence of invasive Centaurea maculosa (spotted knapweed) provides similar benefit to space web dictynid spiders, resulting in greater spider abundance and increased fecundity (Pearson, 2009, 2010). Although space web 


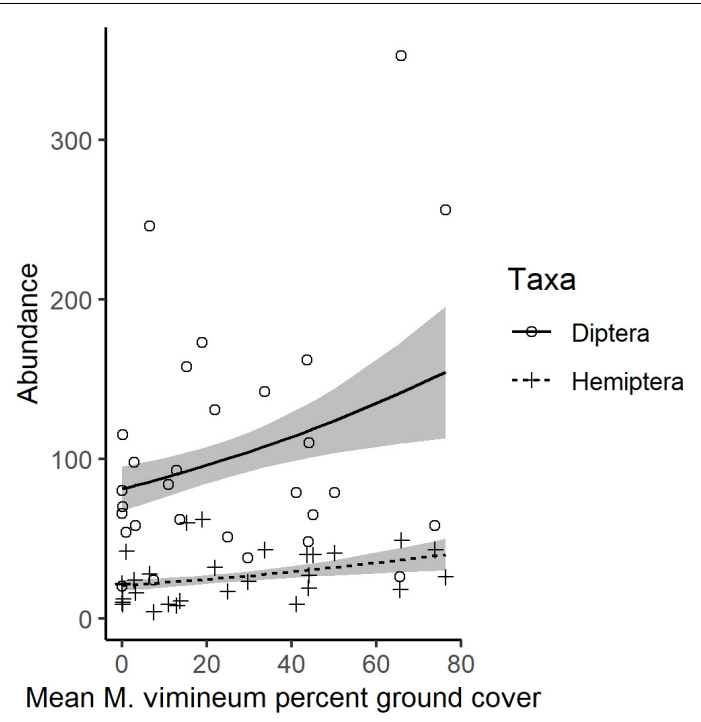

FIGURE 6 | Predicted response of Diptera and Hemiptera with mean percent ground cover of $M$. vimineum. Points represent raw abundance data, lines depict fitted models, and gray shading represents \pm 1 SE.

weaving spiders were positively associated with A. petiolata, this was likely driven to some degree by counts of spiders in several plots with very high levels of $A$. petiolata ground cover. This may indicate an ecological threshold, whereby invasioninduced impacts to invertebrates become more apparent at higher invasive plant densities. Despite being associated with an increase in space web spiders, ground cover of $A$. petiolata had a significant, opposing effect on the relative abundance of the Collembola and Lepidoptera. Collembola, comprised of detritivorous species, may be reduced in abundance with greater A. petiolata ground cover as this plant species has shown to accelerate decomposition of leaf litter (Rodgers et al., 2008) and A. petiolata may reach higher densities in litter-free environments (Bartuszevige et al., 2007). The Lepidoptera include numerous specialist and oligotrophic feeders that are tightly correlated with host plants (Forister et al., 2015; Tallamy et al., 2021) and may therefore avoid areas of dense $A$. petiolata populations. Although correlated with $A$. petiolata and invasive herbs, our invertebrate groups were not significantly correlated with the percent cover of remaining, non-invasive herbaceous plants. This suggests that while $A$. petiolata may functionally represent native plant structure where lacking, the species may augment available structural complexity in habitats where structure already exists.

Invasive shrubs were not correlated with invertebrate community structure or the relative abundance of invertebrate groups, despite their structural complexity. Within the study area, target invasive shrub species were less prevalent than other plant groups, with nearly a third of all plots containing no invasive shrub cover. While we did not detect any significant associations with invasive shrubs, it is possible that we did not detect an effect because few plots were highly invaded (cover or density) by invasive shrubs. However, where invasive shrub cover exceeded $80 \%$, we observed fewer insects and spiders than in comparison with most plots. This could potentially indicate an ecological threshold of invasive plant density, above which point any benefit of added structural complexity is overshadowed by the consequences of such a dense plant population. An examination of invertebrate abundance and community structure across a gradient of invasive shrub density would further elucidate whether such patterns exist.

Relatively small invertebrate sample size could have also limited our ability to detect correlations. With our sampling effort, we were able to detect many of the spider taxa we expected in the study area, though further sampling would certainly result in additional genera (Supplementary Figures 1, 2). That said, our bootstrapped test statistics indicate the strength of the associations we were able to detect. Additionally, these results are corroborated by other published works on invertebrates and these invasive plant species (DeVore and Maerz, 2014; Smith-Ramesh, 2017; Landsman et al., 2020). Finer taxonomic resolution of collected invertebrates may also reveal missed correlations between invasive plants and specific insect and spider taxa. Taxonomic generalizations can facilitate analysis when taxonomic expertise is lacking or when research objectives permit such coarse resolution (Jones, 2008; Groc et al., 2010; Meehan et al., 2019). However, higher level taxonomic groups may be too coarse to detect variation among species or may miss significant correlations (Terlizzi et al., 2009). While our analyses of insect taxonomic orders mirrored the correlations with native plant cover that we noted with morphologically distinct groups, the morphospecies analysis exhibited a much stronger correlation, similar to outcomes noted by Timms et al. (2013). Analysis at the finer scale of morphospecies also uncovered significant correlations with the two prevalent invasive plants, $M$. vimineum and $A$. petiolata, that we did not detect with insect orders. Although we only noted a single significant correlation with individual insect morphospecies and our covariates, finer taxonomic resolution may further detect significant relationships, particularly for groups with broader taxonomic breadth (Mueller et al., 2013).

Despite the importance of prey availability for spiders, the abundance of suitable insect prey was not an important determinant of spider community structure. The importance of plant structure likely outweighs that of prey availability as the prevalent invasive plants are providing structure as a limiting resource in these forests. Both $M$. vimineum and A. petiolata are offering this ecological function which is currently lacking due to a paucity of native understory plants or is insufficient to support greater invertebrate densities (Westman, 1990; Schlaepfer et al., 2011). Targeted invasive plant species comprised much greater ground cover as compared to remaining vegetation in sample plots.

It is clear that benefits of structural subsidy are not without the consequences imposed upon the negatively affected insect taxa. Because of the extent to which structural complexity can affect various arthropod groups, invasive plant species that drastically alter structure may have disproportionately greater effects, either positive or negative (van Hengstum et al., 2014). Additionally, depending on traits of the individual plant species, including growth habit and density, certain invasive plants may pose greater 
ecological risk or benefit to subsequent trophic groups (Hejda et al., 2009). As such, efforts to control invasive plant species must be planned and implemented with consideration of the direct and subsequent impacts of invasion (D'Antonio and Meyerson, 2002; Barney et al., 2013). The distribution of both M. vimineum and $A$. petiolata is rapidly expanding across national parks in the eastern US (Miller et al., 2020). Due to this spread and potential impacts to native vegetation, control of these species, particularly M. vimineum, is noted as a management priority. Impacts of M. vimineum to native vegetation are well known; however, Schmit et al. (2020) documented that M. vimineum may benefit native woody species by providing shelter for tree seedlings in heavily ungulate-browsed forests. The complexities of ecological interactions with invasive plant species necessitate a broader, holistic understanding of the direct and indirect effects to native vegetation and wildlife. Removal of structurally complex invasive plants without remedial habitat restoration or the mitigation of other factors that affect habitat structure may pose significant risks to animal communities which rely on the plant structure (Sogge et al., 2008; Ballari et al., 2019). With regards to the ecological effects of invasive plant species, blanket statements are overly simplistic and potentially misleading. Invasive plant species can fulfill a positive ecological role; however, these incidences are certainly dependent upon a number of factors (Schirmel et al., 2016) and such positive effects may not be experienced equally across all invertebrate or vertebrate taxa.

\section{DATA AVAILABILITY STATEMENT}

The raw data supporting the conclusions of this article will be made available by the authors, without undue reservation.

\section{REFERENCES}

Ballari, S. A., Hendrix, B. D., Sample, M., and Nuñez, M. A. (2019). Management of invasive Pinaceae is imperiled by the lack of invasive ungulate control: successful restoration requires multiple-species management. Mammal Res. 64, 535-542. doi: 10.1007/s13364-019-0 0439-0

Barney, J. N., Tekiela, D. R., Dollette, E. S. J., and Tomasek, B. J. (2013). What is the "real" impact of invasive plant species? Front. Ecol. Environ. 11, 322-329. doi: 10.1890/120120

Bartuszevige, A. M., Hrenko, R. L., and Gorchov, D. L. (2007). Effects of leaf litter on establishment, growth and survival of invasive plant seedlings in a deciduous forest. Am. Midl. Nat. 158, 472-477. doi: 10.1674/0003-0031(2007)158[472: eolloe]2.0.co;2

Bultman, T. L., and DeWitt, D. J. (2008). Effect of an invasive ground cover plant on the abundance and diversity of a forest floor spider assemblage. Biol. Invasions 10, 749-756. doi: 10.1007/s10530-007-9168-z

Burghardt, K. T., Tallamy, D. W., Philips, C., and Shropshire, K. J. (2010). Non-native plants reduce abundance, richness, and host specialization in lepidopteran communities. Ecosphere 1:art11. doi: 10.1890/es10-00032.1

Cardoso, P., Pekár, S., Jocqué, R., and Coddington, J. A. (2011). Global patterns of guild composition and functional diversity of spiders. PLoS One 6:e21710. doi: 10.1371/journal.pone.0021710

Charlebois, J. A., and Sargent, R. D. (2017). No consistent pollinator-mediated impacts of alien plants on natives. Ecol. Lett. 20, 1479-1490. doi: 10.1111/ele. 12831

\section{AUTHOR CONTRIBUTIONS}

AL conceptualized the work and led analysis and manuscript development. JS and EM provided analytic support, vegetation data, and assisted in the drafting of the manuscript. All authors contributed to the article and approved the submitted version.

\section{FUNDING}

This work was wholly funded by the United States Department of the Interior, National Park Service.

\section{ACKNOWLEDGMENTS}

We would like to thank W.M. Ford, Z.S. Ladin, and two reviewers for their helpful and constructive review of this manuscript. We would also like to thank K. Jones for assistance in data collection and insect identification. The views and opinions represented herein are to be considered a work of the authors and not that of the U.S. Department of the Interior. Any use of trade, firm, or product names is for descriptive purposes only and does not imply endorsement by the U.S. Government.

\section{SUPPLEMENTARY MATERIAL}

The Supplementary Material for this article can be found online at: https://www.frontiersin.org/articles/10.3389/fevo.2021. 682140/full\#supplementary-material

Crooks, J. A. (2002). Characterizing ecosystem-level consequences of biological invasions: the role of ecosystem engineers. Oikos 97, 153-166. doi: 10.1034/j. 1600-0706.2002.970201.x

D’Antonio, C. D., and Meyerson, L. A. (2002). Exotic plant species as problems and solutions in ecological restoration: a synthesis. Restor. Ecol. 10, 703-713. doi: 10.1046/j.1526-100x.2002.01051.x

Davison, A. C., and Hinkley, D. V. (1997). Bootstrap Methods and their Application. Cambridge: Cambridge University Press.

DeVore, J. L., and Maerz, J. C. (2014). Grass invasion causes top-down pressure on an amphibian via structurally mediated effects on an intraguild predator. Ecology 95, 1724-1730. doi: 10.1890/13-1715.1

Dudek, K., Michlewicz, M., Dudek, M., and Tryjanowski, P. (2016). Invasive Canadian goldenrod (Solidago canadensis L.) as a preferred foraging habitat for spiders. Arthropod Plant Interact. 10, 377-381. doi: 10.1007/s11829-0169455-7

Dunn, P. K., and Smyth, G. K. (1996). Randomized quartile residuals. J. Comput. Graph. Stat. 5, 236-244.

Dutra, H. P., Barnett, K., Reinhardt, J. R., Marquis, R. J., and Orrock, J. L. (2011). Invasive plant species alters consumer behavior by providing refuge from predation. Oecologia 166, 649-657. doi: 10.1007/s00442-010-1895-7

Forister, M. L., Novotny, V., Panorska, A. K., Baje, L., Basset, Y., Butterill, P. T., et al. (2015). The global distribution of diet breadth in insect herbivores. Proc. Natl. Acad. Sci. U.S.A. 112, 442-447.

Gibson, C. W. D., Hambler, C., and Brown, V. K. (1992). Changes in spider (Araneae) assemblages in relation to succession and grazing management. J. Appl. Ecol. 29, 132-142. doi: 10.2307/2404356 
Grandez-Rios, J. M., Lima Bergamini, L., Santos de Araújo, W., Villalobos, F., and Almeida-Neto, M. (2015). The effect of host-plant phylogenetic isolation on species richness, composition and specialization of insect herbivores: a comparison between native and exotic hosts. PLoS One 10:e0138031. doi: 10. 1371/journal.pone.0138031

Groc, S., Delabie, J. H. C., Longino, J. T., Orivel, J., Majer, J. D., Vasconcelos, H. L., et al. (2010). A new method based on taxonomic sufficiency to simplify studies on Neotropical ant assemblages. Biol. Conserv. 143, 2832-2839. doi: 10.1016/j.biocon.2010.07.034

Harvey, J. A., Biere, A., Fortuna, T., Vet, L. E. M., Engelkes, T., Morriën, E., et al. (2010a). Ecological fits, mis-fits and lotteries involving insect herbivores on the invasive plant, Bunias orientalis. Biol. Invasions 12, 3045-3059. doi: 10.1007/s10530-010-9696-9

Harvey, J. A., Bukovinszky, T., and van der Putten, W. H. (2010b). Interactions between invasive plants and insect herbivores: a plea for a multitrophic perspective. Biol. Conserv. 143, 2251-2259. doi: 10.1016/j.biocon.2010. 03.004

Hejda, M., Pyšek, P., and Jarošík, V. (2009). Impact of invasive plants on the species richness, diversity and composition of invaded communities. J. Ecol. 97, 393-403. doi: 10.1111/j.1365-2745.2009.01480.x

Jones, F. C. (2008). Taxonomic sufficiency: the influence of taxonomic resolution on freshwater bioassessments using benthic macroinvertebrates. Environ. Rev. 16, 45-69. doi: 10.1139/a07-010

Kleiber, C., and Zeileis, A. (2008). Applied Econometrics with R. New York, NY: Springer-Verlag.

Landsman, A. P., and Bowman, J. L. (2017). Discordant response of spider communities to forests disturbed by deer herbivory and changes in prey availability. Ecosphere 8:e01703. doi: 10.1002/ecs2.1703

Landsman, A. P., Burghardt, K. T., and Bowman, J. L. (2020). Invasive grass (Microstegium vimineum) indirectly benefits spider community by subsidizing available prey. Ecol. Evol. 10, 11133-11143. doi: 10.1002/ece3.6752

Langellotto, G. A., and Denno, R. F. (2004). Responses of invertebrate natural enemies to complex-structured habitats: a meta-analytical synthesis. Oecologia 139, 1-10. doi: 10.1007/s00442-004-1497-3

Loomis, J. D., Cameron, G. N., and Uetz, G. W. (2014). Impact of the invasive shrub Lonicera maackii on shrub-dwelling Araneae in a deciduous forest in eastern North America. Am. Midl. Nat. 171, 204-218. doi: 10.1674/0003-0031-171.2. 204

Mack, R. N., Simberloff, D., Lonsdale, W. M., Evans, H., Clout, M., and Bazzaz, F. A. (2000). Biotic invasions: causes, epidemiology, global consequences, and control. Ecol. Appl. 10, 689-710. doi: 10.1890/1051-0761(2000)010[0689: bicegc] 2.0.co;2

Maclagan, S. J., Coates, T., and Ritchie, E. G. (2018). Don't judge a habitat on its novelty: assessing the value of novel habitats for an endangered mammal in a peri-urban landscape. Biol. Conserv. 223, 11-18.

Malo, A. F., Godsall, B., Prebble, C., Grange, Z., McCandless, S., Taylor, A., et al. (2012). Positive effects of an invasive shrub on aggregation and abundance of a native small rodent. Behav. Ecol. 21, 759-767. doi: 10.1093/beheco/ars202

Marshall, J. M., and Buckley, D. S. (2009). Influence of Influence of Microstegium vimineum presence on insect abundance in hardwood forests presence on insect abundance in hardwood forests. Southeast. Nat. 8, 515-526. doi: 10.1656/058. 008.0312

McCary, M. A., Mores, R., Farfan, M. A., and Wise, D. H. (2016). Invasive plants have different effects on trophic structure of green and brown food webs in terrestrial ecosystems: a meta-analysis. Ecol. Lett. 19, 328-335. doi: 10.1111/ ele. 12562

McNett, B. J., and Rypstra, A. L. (2000). Habitat selection in a large orb-weaving spider: vegetation complexity determines site selection and distribution. Ecol. Entomol. 25, 423-432. doi: 10.1046/j.1365-2311.2000.00279.x

Meehan, M. L., Song, Z., Lumley, L. M., Cobb, T. P., and Proctor, H. (2019). Soil mites as bioindicators of disturbance in the boreal forest in northern Alberta, Canada: testing taxonomic sufficiency at multiple taxonomic levels. Ecol. Indic. 102, 349-365. doi: 10.1016/j.ecolind.2019. 02.043

Miller, K. M., McGill, B. J., Weed, A. S., Seirup, C. E., Comiskey, J. A., Matthews, E. R., et al. (2020). Long-term trends indicate that invasive plants are pervasive and increasing in eastern national parks. Ecol. Appl. 31:e02239. doi: 10.1002/ eap.2239
Mueller, M., Pander, J., and Geist, J. (2013). Taxonomic sufficiency in freshwater ecosystems: effects of taxonomic resolution, functional traits, and data transformation. Freshw. Sci. 32, 762-778. doi: 10.1899/12-212.1

Muñoz, A. A., and Cavieres, L. A. (2008). The presence of a showy invasive plant disrupts pollinator service and reproductive output in native alpine species only at high densities. J. Ecol. 96, 459-467. doi: 10.1111/j.1365-2745.2008.01361.x

Nielsen, C., Heimes, C., and Kollmann, J. (2008). Little evidence for negative effects of an invasive alien plant on pollinator services. Biol. Invasions 10, 1353-1363. doi: 10.1007/s10530-007-9210-1

Overton, C. T., Casazza, M. L., Takekawa, J. Y., Strong, D. R., and Holyoak, M. (2014). Tidal and seasonal effects on survival rates of the endangered California clapper rail: Does invasive Spartina facilitate greater survival in a dynamic environment? Biol. Invasions 16, 1897-1914. doi: 10.1007/s10530-013-0634-5

Pearson, D. E. (2009). Invasive plant architecture alters trophic interactions by changing predator abundance and behavior. Oecologia 159, 549-558. doi: 10 . 1007/s00442-008-1241-5

Pearson, D. E. (2010). Trait- and density-mediated indirect interactions initiated by an exotic invasive plant autogenic ecosystem engineer. Am. Nat. 176, 394-403. doi: 10.1086/656274

Pétillon, J., Puzin, C., Acou, A., and Outreman, Y. (2009). Plant invasion phenomenon enhances reproduction performance in an endangered spider. Naturwissenschaften 96, 1241-1246. doi: 10.1007/s00114-009-0589-7

Pétillon, J., Ysnel, F., Lefeuvre, J.-C., and Canard, A. (2005). Are salt marsh invasions by the grass Elymus athericus a threat for two dominant halophilic wolf spiders? J. Arachnol. 33, 236-242. doi: 10.1636/ct-04-121.1

R Core Team (2020). R: A Language and Environment for Statistical Computing. Vienna: R Foundation for Statistical Computing.

Rodgers, V. L., Wolfe, B. E., Werden, L. K., and Finzi, A. C. (2008). The invasive species Alliaria petiolata (garlic mustard) increases soil nutrient availability in northern hardwood-conifer forests. Oecologia 157, 459-471. doi: 10.1007/ s00442-008-1089-8

Rodriguez, L. F. (2006). Can invasive species facilitate native species? Evidence of how, when, and why these impacts occur. Biol. Invasions 8, 927-939. doi: 10.1007/s10530-005-5103-3

Schirmel, J., Bundschuh, M., Entling, M. H., Kowarik, I., and Buchholz, S. (2016). Impacts of invasive plants on resident animals across ecosystems, taxa, and feeding types: a global assessment. Glob. Change Biol. 22, 594-603. doi: 10.1111/ gcb.13093

Schlaepfer, M. A., Sax, D. F., and Olden, J. D. (2011). The potential conservation value of non-native species. Conserv. Biol. 25, 428-437. doi: 10.1111/j.15231739.2010.01646.x

Schmidt, J. M., and Rypstra, A. L. (2010). Opportunistic predator prefers habitat complexity that exposes prey while reducing cannibalism and intraguild encounters. Oecologia 164, 899-910. doi: 10.1007/s00442-010-1785-z

Schmit, J. P., Matthews, E. R., and Brolis, A. (2020). Effects of culling white-tailed deer on tree regeneration and Microstegium vimineum, an invasive grass. For. Ecol. Manage. 463:118015. doi: 10.1016/j.foreco.2020.118015

Schmit, J. P., Sanders, G., Lehman, M., Paradis, T., and Matthews, E. (2014). National Capital Region Network Long-Term Forest Vegetation Monitoring Protocol: Version 2.1. Natural Resource Report NPS/NCRN/NRR-2009/113. Fort Collins, CO: United States National Park Service.

Shriver, W. G., Ladin, Z. S., Buler, J., and D'Amico, V. (2021). Non-native shrubs and calcium availability are important for birds breeding in urban forests. Urban Ecosyst. 24, 429-440. doi: 10.1007/s11252-020-01049-4

Simberloff, D. (2011). How common are invasion-induced ecosystem impacts? Biol. Invasions 13, 1255-1268. doi: 10.1007/s10530-011-9956-3

Simberloff, D., and Gibbons, L. (2004). Now you see them, now you don't! Population crashes of established invasive species. Biol. Invasions 6, 161-172. doi: 10.1023/b:binv.0000022133.49752.46

Smith, L. M., and Schmitz, O. J. (2015). Invasive plants may promote predatormediated feedback that inhibits further invasion. Ecol. Evol. 5, 2411-2419. doi: 10.1002/ece3.1525

Smith-Ramesh, L. M. (2017). Invasive plant alters community and ecosystem dynamics by promoting native predators. Ecology 98, 751-761. doi: 10.1002/ ecy. 1688

Sogge, M. K., Sferra, S. J., and Paxton, E. H. (2008). Tamarix as habitat for birds: implications for riparian restoration in the southwestern United States. Restor. Ecol. 16, 146-154. doi: 10.1111/j.1526-100x.2008.00357.x 
Spafford, R. D., Lortie, C. J., and Butterfield, B. J. (2013). A systematic review of arthropod community diversity in association with invasive plants. NeoBiota 16, 81-102. doi: 10.3897/neobiota.16.4190

Stevens, D. L., and Olsen, A. R. (2004). Spatially balanced sampling of natural resources. J. Am. Stat. Assoc. 99, 262-278. doi: 10.1198/016214504000000250

Stubbs, C. S., Drummond, F., and Ginsberg, H. (2007). Effects of Invasive Plant Species on Pollinator Service and Reproduction in Native Plants at Acadia National Park. Technical Report NPS/NER/NRTR-2007/096. Boston, MA: United States National Park Service.

Tallamy, D. W., Ballard, M., and D'Amico, V. (2010). Can alien plants support generalist insect herbivores? Biol. Invasions 12, 2285-2292. doi: 10.1007/ s10530-009-9639-5

Tallamy, D. W., Narango, D. L., and Mitchell, A. B. (2021). Do non-native plants contribute to insect declines? Ecol. Entomol. 46, 729-742. doi: 10.1111/een. 12973

Tallamy, D. W., and Shropshire, K. J. (2009). Ranking lepidopteran use of native versus introduced plants. Conserv. Biol. 23, 941-947. doi: 10.1111/j.1523-1739. 2009.01202.x

Terlizzi, A., Anderson, M. J., Bevilacqua, S., Fraschetti, S., Włodarska-Kowalczuk, M., and Ellingsen, K. E. (2009). Beta diversity and taxonomic sufficiency: Do higher-level taxa reflect heterogeneity in species composition? Divers. Distrib. 15, 450-458. doi: 10.1111/j.1472-4642.2008.00551.x

Timms, L. L., Bowden, J. J., Summerville, K. S., and Buddle, C. M. (2013). Does species-level resolution matter? Taxonomic sufficiency in terrestrial arthropod biodiversity studies. Insect Conserv. Divers. 6, 453-462 doi: 10.1111/icad.12004

Triplehorn, C. A., and Johnson, N. F. (2005). Borror and DeLong's Introduction to the Study of Insects, 7th Edn. Belmont, CA: Thompson Brooks/Cole.

Ubick, D., Paquin, R., Cushing, P. E., and Roth, V. (2017). Spiders of North America: An Identification Manual, 2nd Edn. Keene, NH: American Arachnological Society.

Valentine, L. E., Ramalho, C. E., Mata, L., Craig, M. D., Kennedy, P. L., and Hobbs, R. J. (2020). Novel resources: opportunities for and risks to species conservation. Front. Ecol. Environ. 18, 558-566. doi: 10.1002/fee.2255

van Hengstum, T., Hooftman, D. A. P., Oostermeijer, J. G. B., and van Tienderen, P. H. (2014). Impact of plant invasions on local arthropod communities: a meta-analysis. J. Ecol. 102, 4-11. doi: 10.1111/1365-2745.12176
Venables, W. N., and Ripley, B. D. (2002). Modern Applied Statistics with S, 4th Edn. New York, NY: Springer-Verlag.

Wang, Y., Naumann, U., Wright, S. T., and Warton, D. I. (2012). mvabund - an $\mathrm{R}$ package for model-based analysis of multivariate abundance data. Methods Ecol. Evol. 3, 471-474. doi: 10.1111/j.2041-210x.2012.00190.x

Watling, J. I., Hickman, C. R., and Orrock, J. L. (2011). Invasive shrub alters native forest amphibian communities. Biol. Conserv. 144, 2597-2601. doi: 10.1016/j. biocon.2011.07.005

Westfall, P., and Young, S. (1993). Resampling-Based Multiple Testing. New York, NY: John Wiley and Sons.

Westman, W. E. (1990). Park management of exotic plant species: problems and issues. Conserv. Biol. 4, 251-260. doi: 10.1111/j.1523-1739.1990.tb0 0286.x

Williamson, M., and Fitter, A. (1996). The varying success of invaders. Ecology 77, 1661-1666. doi: 10.2307/2265769

Wolf, K. M., Whalen, M. A., Bourbour, R. P., and Baldwin, R. A. (2017). Rodent, snake and raptor use of restored native perennial grasslands is lower than use of unrestored exotic annual grasslands. J. Appl. Ecol. 55, 1133-1144. doi: $10.1111 / 1365-2664.12990$

Conflict of Interest: The authors declare that the research was conducted in the absence of any commercial or financial relationships that could be construed as a potential conflict of interest.

Publisher's Note: All claims expressed in this article are solely those of the authors and do not necessarily represent those of their affiliated organizations, or those of the publisher, the editors and the reviewers. Any product that may be evaluated in this article, or claim that may be made by its manufacturer, is not guaranteed or endorsed by the publisher.

Copyright (C) 2021 Landsman, Schmit and Matthews. This is an open-access article distributed under the terms of the Creative Commons Attribution License (CC BY). The use, distribution or reproduction in other forums is permitted, provided the original author(s) and the copyright owner(s) are credited and that the original publication in this journal is cited, in accordance with accepted academic practice. No use, distribution or reproduction is permitted which does not comply with these terms. 